\title{
A justiça restaurativa como mecanismo de horizontalização de conflitos penais e de reconhecimento das vítimas como sujeito de direitos
}

\author{
Restorative justice as a mechanism for horizontalization of penal \\ conflicts and recognition of victims as subjects of rights
}

\author{
Flaviane de Magalhães Barros Bolzan de Morais ${ }^{1}$ \\ Universidade Federal de Ouro Preto/MG \\ Pontifícia Universidade Católica de Minas Gerais/MG \\ barros.flaviane@gmail.com \\ http://lattes.cnpq.br/1159840059123495 \\ Dich://orcid.org/0000-0002-2377-6026
}

\section{José Afonso Neto ${ }^{2}$}

Universidade Federal de Ouro Preto/MG afonsodireito@yahoo.com.br

http://lattes.cnpq.br/7726738456433508

D. http://orcid.org/0000-0002-2108-2776

\section{Yollanda Farnezes Soares ${ }^{\mathbf{3}}$}

Universidade Federal de Ouro Preto/MG

yfarnezes@hotmail.com

http://lattes.cnpq.br/3790077017799743

http://orcid.org/0000-0003-0114-1828

1 Doutora e Mestre em Direito Processual pela PUC Minas, com estágio pós-doutoral junto a Università degli studi di Roma Tre (CAPES), professora visitante junto a Università degli studi di Firenze. Bolsista de Produtividade de CNPq. Coordenadora Adjunta de Mestrados Profissionais, CAPES, área Direito. Professora do Programa de Pós-graduação da PUC Minas e da UFOP.

2 Mestrando em Direito pela Universidade Federal de Ouro Preto - UFOP. Graduado em Direito pela Faculdade de Direito da Universidade Federal de Minas Gerais UFMG. Juiz de Direito do Tribunal de Justiça do Estado de Minas Gerais (TJMG).

3 Mestranda e Graduada em Direito pela Universidade Federal de Ouro Preto. Advogada. 
RESUMO: Este artigo discute a necessidade de superação do modelo processual penal fundamentado na neutralização da vítima e consequente expropriação do conflito pelo Estado, como fórmula única para solução do caso penal. Com foco nesse modelo processual, questiona-se se a sua lógica de fato atende às necessidades das vítimas, respeitando seus direitos e garantias fundamentais. Em seguida, indaga-se sobre a necessidade de se discutir, ainda que de forma coadjuvante ao modelo vigente, um novo modelo de solução consensual de conflitos penais, marcado pela construção de procedimentos dialógicos e horizontais como forma de resposta ao delito. Para tanto, o presente artigo possui como marco a noção de justiça horizontalizada, apontada por Nils Christie, que trabalha a importância de se construir uma justiça que se atenha às especificidades dos personagens centrais do conflito penal - ofensores e vítimas - para uma construção participada na decisão do caso penal. Por fim, analisa-se se a Justiça Restaurativa tem potencial suficiente para conferir a autonomia necessária às vítimas para que sejam, efetivamente, compreendidas como sujeitos de direitos.

Palavras-Chave: Vítima; Justiça Horizontalizada; Justiça Restaurativa.

ABSTRACT: This article discusses the need to overcome the criminal procedural model based on the neutralization of the victim and the consequent expropriation of the conflict by the State, as the only formula for solving the criminal case. Focusing on this procedural model, it is questioned whether its logic actually meets the needs of victims, respecting their fundamental rights and guarantees. The next question is about the urge to discuss, even in a way that is compatible with the current model, a new model of consensual solution of criminal conflicts, marked by the construction of dialogical and horizontal procedures as a response to crime. This article is based on the notion of horizontal justice, pointed out by Nils Christie, which demonstrates the importance to build a justice that fits the specificities of the central characters of the criminal conflict - offenders and victims - to a participative decision of the criminal case. Finally, it is analyzed if the Restorative Justice has sufficient potential to confer the necessary autonomy to the victims so that they are effectively understood as subject of rights.

KeYwords: Victim; Horizontal Justice; Restorative Justice.

SUMÁRIO: Introdução; 1. Jurisdição Penal e a neutralização da vítima; 2. A Justiça Horizontalizada como diretriz para a Justiça Restaurativa; 3. A Justiça Restaurativa e o protagonismo da vítima como sujeito de direitos; Considerações Finais; Referências. 


\section{INTRODUÇÃO}

A temática da vitimologia vem sendo estudada ao longo dos anos, porém ganhou amplitude mais precisamente após a década de 1970, com a crise do Estado social e o advento do Estado Democrático de Direito. O movimento vitimológico passou a se preocupar com o papel da vítima de delitos para que ela não fosse simplesmente anulada, alijada da solução do conflito penal, porque afetada diretamente pelo ato criminoso, não podendo, dessa forma, ser invisibilizada na solução processual penal da infração, ser relegada às margens da solução do conflito, sem nele poder efetivamente influir. Tratou-se de uma nova perspectiva contra $o$ esquecimento secular das vítimas.

O ponto crucial do movimento vitimológico condensou-se, nessa linha, na crítica à neutralização da vítima pelo processo penal, justamente pelo fato de o Estado expropriar o conflito das suas partes originárias (autor e vítima) e se colocar como sujeito passivo constante dos crimes. Trata-se de expropriação no âmbito processual, que afasta a vítima da solução do conflito, porquanto, não obstante a vítima, em grande parte dos casos, seja a parte primária da relação de Direito Penal, assume o Estado, como protagonista, o papel de condutor dos julgamentos, aplicador das sanções e fiscalizador das penas. De certo, essa neutralização teve sua relevância histórica em termos de controle de retribuições para mitigação de punições desproporcionais e desarrazoadas impostas aos infratores. Porém, nas lindes do Estado Democrático de Direito, essa perspectiva não se mostra mais constitucionalmente adequada, porquanto outros são os norteadores das relações entre os sujeitos e com o Estado - os valores que permeiam a conformação desse modelo de democracia não se coadunam com o silenciamento da vítima.

Tanto é assim, como se pretende desenvolver nesse artigo, que se faz necessário discutir sobre uma nova forma de justiça, que leve a sério direitos e garantias da vítima, que a compreenda como sujeito de direitos, respeitada a sua autonomia, visto que o sistema jurisdicional brasileiro, mesmo com as reformas do Código de Processo Penal, não confere à vítima a emancipação necessária para contribuir na solução do caso concreto de maneira satisfatória. Portanto, é urgente dialogar sobre novos modelos de justiça, que devolvam à vítima o protagonismo usurpado pelo Estado, ainda mais quando se compreende que a 
univocidade de resposta estatal aos inúmeros e diferentes conflitos penais, consistente, quase sempre, na imposição de pena aflitiva, desconsidera as subjetividades dos envolvidos no conflito. Isto é, para os mais variados conflitos penais, com os mais diversos autores e vítimas, a única e insatisfatória resposta estatal tem sido a imposição de uma pena, que não raras vezes não supre as expectativas dos atingidos pela decisão judicial.

O objetivo desse trabalho volta-se justamente a demonstrar como o modelo jurisdicional atual contém falhas na tratativa do conflito penal (ACHHUTTI; PALLAMOLA, 2017, p. 284), especialmente porque estruturado de forma centralizadora, num processo vertical decisório, incapaz de dar a autonomia necessária às vítimas para que sejam compreendidas como sujeito de direitos quanto à solução dos conflitos penais. Traçado esse plano, se analisará a Justiça Restaurativa como uma das possibilidades de se efetivar uma nova forma de justiça (CAMPANÁRIO, 2013, p. 120), em virtude de seu potencial dialógico e horizontal, vez que se realiza mediante construção coletiva e participada da solução, específica ao caso concreto, pelos envolvidos diretos no conflito processual penal

Questiona-se, portanto, se a lógica processual penal vigente, que almeja a pena como resposta estatal padrão, de fato atende às necessidades das vítimas, ou se, em outra leitura, as torna duplamente perdedoras, por sofrerem a ação do agressor e padecerem do esquecimento estatal. Na sequência, indaga-se por que não se discutir um novo modelo de solução consensual de conflitos penais, marcado pela construção de um instrumento dialógico e horizontal para a solução de conflitos: a Justiça Restaurativa. Trata-se de modelo que busca uma resposta que seja adequada a cada caso concreto, desvinculando-se da pena como única possibilidade de solução, porque compreende o viés da reparação e as mais diversas possibilidades de resolução do conflito penal.

Para tanto, em perspectiva metodológica analítica, será necessário contextualizar a neutralização da vítima por parte do Estado, presente no modelo jurisdicional vigente; em seguida, se apresentará a concepção de justiça horizontalizada de Nils Christie (1977; 2011); e, por fim, se analisará se existe potencial emancipatório na Justiça Restaurativa, especialmente para as vítimas. 


\section{JURISDIÇÃo PENAL E A NEUTRALIZAÇÃo DA VÍTIMA}

O papel da vítima no conflito penal compreende três grandes fases (GOMES; MOLINA: 2000, p. 73): protagonismo, neutralização e redescoberta.

Para fins desse trabalho, serão apontadas as características marcantes de cada uma dessas fases, sem preocupação com a sua evolução histórica, somente para se compreender a fase da neutralização da vítima no processo penal e os seus efeitos perniciosos, abrindo-se espaço, nessa viragem de redescoberta, a outras formas de realização da justiça penal, mais afeitas ao tratamento constitucional da vítima que, no Estado Democrático de Direito, há de ser reconhecida com sujeito de direitos (BARROS, 2013, p. 311).

Na primeira fase, era o tempo da vingança privada, em que competia à vítima a incumbência de valer-se dos meios que dispusesse para contrapor-se à infração sofrida. Tratava-se da retribuição do mal com o mal - imposição de um novo prejuízo para compensação daquele que foi sofrido, sem observância de quaisquer formalidades e sem adstrição à razoabilidade da medida retributiva à ofensa causada. Em virtude da necessidade de controle no uso da vingança privada, especialmente sob a ótica da paz social, ainda nessa fase de protagonismo, surgiu a justiça privada, com a finalidade de estabelecimento de proporcionalidade entre a agressão do ofensor e a retribuição da vítima, e, também, para permitir a composição como medida de reparação do dano (ANITUA, 2008). Não obstante, era a vítima a detentora do destino do ofensor, sem interferência de autoridade.

Em um segundo momento, revelando-se ainda mais premente a necessidade de controle da vingança privada e em razão da preocupação dos governantes com seus interesses, paulatinamente tomou forma a justiça pública, que ocupou o espaço da vingança privada e da justiça privada (ANITUA, 2008; BERNISTEIN, 2000, p. 74). Nesse período é que se concretiza, pouco a pouco, dada a expropriação do conflito pelo Estado, o processo de neutralização da vítima, que, outrora parte condutora da persecução penal, torna-se mera informadora do delito. Trata-se de estágio longo, que se estende desde o Direito Romano, perpassa a Idade Média, a formação dos Estados Nacionais, rompendo o tempo até o século XX. 
A conformação do processo penal nessa fase promoveu o esquecimento da vítima, porquanto não havia espaço para ela na triangulação acusado, acusador e juiz. À vítima relegou-se espaço à margem do conflito, dela usurpado (ANITUA, 2008; SANTANA, 2009, p 324).

Na terceira fase, a partir dos estudos da vitimologia, especialmente após a Segunda Guerra Mundial, a vítima começa a ressurgir do ostracismo, em um primeiro momento pelas discussões decorrentes do holocausto do povo judeu (JUNIOR, 1993). Na década de 70, com o movimento feminista e, na seara do Direito Penal, com o movimento abolicionista (BARROS, 2013, p. 319), apontaram-se duros questionamentos a respeito do papel atribuído pelas legislações às vítimas de delitos. Igualmente contribuiu a esse alargamento da discussão a reanalise do lugar da vítima sob as luzes do Estado Democrático de Direito, especialmente por sua ótica de legitimação procedimentalista, em que se indica que os afetados participem do processo de discussão das soluções, porque cada sujeito de direito é, ao mesmo tempo, autor e destinatário das formas jurídicas (HABERMAS, 1997).

De certo, essa redescoberta não significou o reencontro histórico daquela mesma vítima da fase de protagonismo, com os poderes então a ela atribuídos, no entanto, os estudos permitiram o levantamento dos véus da invisibilidade, reconhecendo-se que a neutralização da vítima, pela expropriação do conflito, não se mostrava adequada ao tratamento desse sujeito no paradigma do Estado Democrático de Direito.

A neutralização do conflito não se compatibiliza com as diretivas irradiantes do princípio da dignidade da pessoa humana, porque é direito fundamental da vítima a possibilidade de participação ativa na busca de realização de seus direitos de forma integral (SOUZA, 2016, p. 24), incluindo-se assim os direitos fundamentais relacionados ao processo penal. A despersonificação do conflito, expropriado pelo Estado, não possibilita a participação democrática na solução penal e não garante a proteção necessária à vítima, violando-se assim seus direitos fundamentais.

Uma nova definição do papel da vítima, diversa da neutralização do conflito, pode ter significativo impacto quanto à criação de sentido para as partes (SCHUCH, 2009, p. 10), especialmente para vítima, porquanto, em um conflito em que se reconhecem as subjetividades dos envolvidos, o sentido do crime há de ser reconstruído a partir das perspectivas e 
experiências dos que por ele mais foram afetados - vítima e infrator (ZEHR; TOWES, 2006, p. 419). Trata-se de sentido que não decorre de interventores externos, mas que parte dos sujeitos que experienciaram a situação de vulneração e dela podem extrair conclusões para si, para o Estado e para os demais membros da sociedade,

Para o criminólogo norueguês Nils Christie: "la victima es una especie de perdedora por partida doble, primero, frente al delincuente, y segundo (...) al serle denegado el derecho a la plena participación en lo que podan haber sido uno de los encuentros rituales más importantes de su vida" (CHRISTIE, 1977, p. 162-163). A partir desse contexto, a justificação para a superação do modelo processual baseado na expropriação do conflito decorre da compreensão da necessidade de se estabelecer o que Nils Christie aponta como justiça horizontal (CHRISTIE, 2011, p. 118). Para o autor a justiça horizontal estrutura-se no sentido de que a reparação é mais importante que a retribuição, ou seja, a construção de uma solução adequada ao conflito penal se dá pelas partes, em contrapartida à pena imposta verticalmente pelo Estado, como se verá a seguir.

Compreender as críticas quanto à neutralização da vítima, trazendo-se ao debate a proposta de horizontalização da justiça de Nils Christie (1997; 2011), torna-se relevante para justificar uma revisão do sistema de justiça penal para a atualidade, o que será demonstrado no próximo item do presente estudo.

\section{A JUSTIÇA HORIZONTALIZADA COMO DIRETRIZ PARA A JUSTIÇA RESTAURATIVA}

O sistema de justiça penal que se estrutura a partir da neutralização da vítima recebe diversas críticas. O presente texto utiliza como marco, para formulação da crítica, os estudos de Christie (1977; 2011), que enfatiza a marginalização de autores e vítimas como uma das consequências deletérias da apropriação estatal do conflito.

Num primeiro momento, é importante compreender que a noção de delito apresenta-se posteriormente à ideia de conflito. Em outras palavras, antes de existir o crime como compreendido pelo sistema de justiça criminal, havia o conflito entre as partes. O delito, assim, é a forma 
como o conflito entre as partes é entendido pela linguagem do sistema jurídico. Ainda, deve-se salientar que o conflito não é necessariamente negativo, pois, como o autor aponta, ele pode nos matar, mas sua escassez, em nossa sociedade industrializada atual, pode nos paralisar (CHRISTIE, 1977, p.159). Nessa linha, não se deve compreender o conflito por um viés estritamente negativo, mas perceber nele, também, um mecanismo de desenvolvimento social.

Christie aponta que, no sistema de justiça, aqueles que lidam com o conflito são pessoas completamente alheias a ele, e alheias às próprias partes, como juízes, advogados e promotores, que são, em suma, os profissionais da administração do conflito. A vítima acaba por ser tão marginalizada em sua própria realidade conflituosa que, na maioria dos procedimentos jurídicos, ela é reduzida a mera informante, perdendo completamente a plena participação na resolução do conflito, que é entregue completamente nas mãos do Estado (CHRISTIE, 1977, p. 162-163).

Em uma crítica aos tribunais, o autor assevera que a realidade da justiça criminal é pesada, comum e rotineira, e depois de um certo tempo, manifestamente tediosa (CHRISTIE, 1977, p. 161). Nesse ambiente, em que são tratados inúmeros conflitos penais, tão diferentes e específicos pelas partes que os compõem, seriam necessárias respostas e soluções adequadas e singulares a cada caso, mas que acabam sendo uniformes e padronizadas - produtos de uma justiça de massas (CHHUTTI; PALLAMOLA, 2014, p. 80).

O ambiente dos tribunais, as complexidades de suas arquiteturas, localização e sua estética (AMODIO, 2016) também tendem a afastar ainda mais as partes, que não se identificam e não se sentem à vontade com o espaço destinado à solução de seus conflitos. Os espaços são pensados e construídos para os próprios administradores da lei, marginalizando mais uma vez as vítimas e ofensores - partes primordiais no conflito social (CHRISTIE, 1977, p. 162). O próprio rito processual e sua linguagem tornam o processo inacessível, não permitindo que acusados e vítimas compreendam efetivamente seus lugares e seus papéis (AMODIO, 2016).

A partir desse contexto, Christie defende a necessidade de se devolver o conflito às partes, por meio de uma estrutura descentralizada, cujos principais envolvidos sejam os próprios interessados essenciais da disputa. Por isso se diz da necessidade de profanação do monopólio da 
fala (SALM; SILVA, 2012, p. 200), no sentido de atribuição, aos envolvidos no conflito, de voz para solucioná-lo. O autor do conflito deve ser o responsável por reparar o dano causado à vítima, na busca de uma solução possível e adequada em cada caso concreto.

Christie explica que os conflitos foram usurpados das partes pelo Estado e a própria conformação do processo penal revelaria essa expropriação, porquanto autor e vítima são representados, eles não agem por si sós, não são personagens centrais na persecutória criminal. Os profissionais jurídicos ocupam esses papéis de centralidade durante a administração do conflito pelo Estado e as partes nem sequer assistem o desenrolar e solução do próprio caso (CHRISTIE, 1977, p.162).

$\mathrm{Na}$ atuação punitiva do Estado, o conflito deixa de ser importante. Consequentemente, reduz-se a atenção às partes e, nesse sentido, o criminoso é convertido em objeto de estudo, manipulação e controle - foca-se no sistema de controle do delito. De outro lado, aparta-se a vítima, reduzindo-a a uma não-entidade, a uma coisa (CHISTIE, 1977, p. 165) - mera memória do conflito.

Para o autor, os conflitos são subtraídos por profissionais, por especialistas, especialmente advogados, que silenciam as partes e utilizam a técnica, numa manipulação dos conflitos, para dar uma resposta jurídica à violação penal. O criminólogo aponta que "los conflictos del delito se han transformado en una pertinencia de otras personas - principalmente de los abogados - o han sido redefinidos en interés de otras personas" (CHISTIE, 1977, p. 165).

O ponto central da crítica do sistema de justiça criminal feita por Christie reside exatamente na ideia de que as partes envolvidas no conflito, as quais deveriam participar adequadamente da sua solução, principalmente a vítima por ter sofrido um dano, são excluídas da discussão, nela não podendo efetivamente influir - sujeitos tornados objetos na estrutura processual penal.

O autor explicita que, na sociedade do final do século XX, pelo seu patamar de industrialização, as pessoas vivenciam uma espécie de despersonalização da vida social (CHRISTIE, 1977, p.166-167), fazendo com que se reconheçam umas as outras pelos papéis sociais que ocupam, o que significa a apreensão de meros retalhos do ser, não como pessoas completas e suas personalidades. Em razão disso, as pessoas têm informações limitadas 
umas sobre as outras, ou seja, elas não se conhecem mais. E pelo fato de não se conhecerem, não se importam umas com as outras, assumindo, nessa linha, posições de afastamento frente a uma situação conflituosa. Nessa conjuntura capitalista, a sociedade marca-se pela despersonalização, impondo-se, então, uma necessidade de se livrar rapidamente do conflito, pois ele se assume feições eminentemente negativas, contexto em que os especialistas acabam por apropriar o manejo e solução dos conflitos delituosos. É a ressignificação da neutralidade, relegitimada.

A sociedade analisada por Christie em seus estudos, aprofundada em dilemas individuais, conjuga-se, atualmente, com a crise do mundo ocidental, apresentada por Hardt e Negri, que impacta a relação da opinião pública e das pessoas sobre o processo penal, em especial quanto à formulação de uma resposta punitivista e retributiva para o crime. Duas das subjetividades propostas, nos estudos dos referidos autores, são relevantes para se discutir o atual estado de degradação que o processo penal tem evidenciado. A primeira é a figura do mediatizado, que é aquele sufocado pelo excesso de informação, mas que não possui, por isso mesmo, capacidade para criar informação viva, é um reprodutor de informações mortas (HARDT; NEGRI, 2014, p. 10-12), que está sempre a pedir punição ou invocar clemência. A segunda figura é o securitizado, pessoa movida basicamente pelo medo, o que a faz aceitar estar em uma sociedade prisional, vivendo em um estado de exceção. A figura do securitizado dialoga com a construção de subpapéis: o presidiário e o guarda, o vigia e o vigiado, o autor do crime e a vítima, objeto e sujeito de vigilância. Assim, em cada momento ou situação uma pessoa se move de uma das duas figuras para a outra, passando de autor para vítima ou vice-versa (HARDT; NEGRI, 2014, p. 33-39).

Desse modo, continua atual a análise que Christie faz da questão da vítima e do ofensor e da sua ocultação como personagens do conflito. $\mathrm{O}$ autor compreende que o atual sistema de controle punitivo representa uma grande perda para as partes em relação ao tratamento do conflito, principalmente para a vítima, pois é o Estado, a partir de uma compreensão neutralizada do processo penal, que faz com que a vítima seja impossibilitada de participar na própria discussão penal.

Ademais, a grande perdedora, além da própria vítima, é a sociedade, que acaba esvaziando-se da oportunidade de discussão e esclarecimento 
das normas; uma perda de uma possibilidade pedagógica de se discutir o que representa a lei, de se discutir o que é realmente importante na solução dos conflitos penais, o que é de fato considerado relevante nos casos específicos para a compensação (não só material) das vítimas (CHRISTIE, 1977, p. 170-171).

De certo, uma das possibilidades que a Justiça Restaurativa apresenta são os encontros personalizados (CHRISTIE, 1977, p. 171) como uma resposta para o problema da marginalização da vítima. No entanto, no atual estágio, a vítima é tão esquecida e marginalizada que sequer tem contato com o ofensor, o que é dificultado, ademais, pela assunção do estereótipo clássico de criminoso em relação ao ofensor, sendo que a vítima, de outro lado, passa a ter uma imagem de não-pessoa.

Esse ponto levantado pelo autor é crucial para se entender a dificuldade do sistema de justiça criminal, como é concebido atualmente, de lidar com o conflito penal a fim de se chegar a uma solução ideal para cada conflito. Da neutralização da vítima pelo Estado, em que o conflito acaba por ser expropriado por essa autoridade central, que passa a representá-la, assumindo completamente sua posição, decorre a subjugação da vítima, como figura débil - vítima fraca e reificada -, incapaz de estabelecer um diálogo possível com o ofensor para uma construção horizontal da decisão. Dessa forma, a vítima é silenciada, o autor é tratado de forma estigmatizada e o conflito passa a ser assumido pelos especialistas, numa imposição vertical da decisão da autoridade central.

Não se questiona que o reencontro do agressor com a vítima pode ser um processo de experiência dolorosa, em que, não obstante, em uma primeira reação, induza ao distanciamento, pode, num segundo momento, tornar-se positivo (CHRISTIE 1977, p. 170-171). Para tanto, é necessário que a situação se molde de tal forma que o ponto central da interação não se restrinja à simples atribuição de culpa, mas a uma discussão aprofundada do que poderia ser feito para se mudar a situação, a partir da reintrodução da vítima na história do seu próprio conflito. Nesse sentido, poder-se-ia ser discutido como se atribuir atenção às perdas da vítima e como essas perdas poderiam ser atenuadas. Dessa forma, o ofensor, a partir de um diálogo com a vítima, repassando as causas, condições e circunstâncias do conflito (FERNANDEZ, 2014, p. 24), assume a posição de ouvinte, existindo, inclusive, a possibilidade de ser perdoado. 
A Justiça Restaurativa tem o seu clímax no encontro interpessoal, isto é, no diálogo autêntico (PELIZZOLI, 2016), que somente pode ser realizado por aqueles que se consideram sujeitos de direitos e protagonistas dos próprios destinos. Assim, tanto vítima quanto agressor, assumindo a consciência de seus papéis, podem conduzir à construção da solução penal, específica para o caso concreto, própria da violação subjetiva reconstruída nesse encontro face a face propiciado pela Justiça Restaurativa.

A gestão dos conflitos de forma horizontal pelas partes, por intermédio do encontro pessoal entre vítima e ofensor, é discutido por Nils Christie (1977, p. 174-175) a partir de um raciocínio de julgamento local, numa organização orientada pela vítima, em que, em primeiro lugar, deveria ser recuperado cada detalhe vivenciado pela vítima sobre o que aconteceu, minúcias de onde se pode (ou não) extrair relevância jurídica. Num segundo momento, haveria uma consideração meticulosa sobre o que poderia ser feito para e pela vítima, pelo ofensor, pela comunidade e pelo Estado. Num terceiro momento, discutir-se-ia se o dano sofrido pela vítima poderia ser compensado, não só financeiramente. Nesse sentido, o criminólogo aponta para uma organização sistemática, aproximando-se de uma composição civil, dialogada e participada por todos os envolvidos no conflito. Por último, após a tomada de decisão local, haveria a preocupação para uma assistência ao ofensor, numa avaliação pessoal e social, pelo viés educativo, médico e até religioso. Essa avaliação da situação social do ofensor não se daria para evitar futuros crimes, mas porque, conforme aponta Christie, as necessidades devem ser enfrentadas (CHRISTIE, 1977, p.175).

Destaque-se, contudo, que nem sempre será possível esse encontro interpessoal da vítima e ofensor, o que não impede a utilização de outras técnicas restaurativas, como os processos circulares (PRANIS, 2010). Ainda que se trate de uma prática com participação indireta da vítima, pode ela ver atendidos os seus anseios, dado o caráter responsabilizador da Justiça Restaurativa, que não se esgota em uma função exclusivamente punitiva, mas conduz o infrator a tomada de consciência sobre os próprios atos e seus reflexos sobre os outros. As técnicas restaurativas são também performativas para o autor do delito e para a sociedade, contendo mensagens específicas para os envolvidos no conflito e também para a comunidade. 
Na concepção de justiça local ou tribunais comunitários não se admite a ideia de especialização. A especialização na resolução de conflitos é negativa, pois a especialização leva a profissionalização $(\mathrm{CH}-$ RISTIE 1977, p. 170-171). Os especialistas são treinados e têm o poder de manipular argumentos, de modo que, para Christie, faz-se necessário reduzir ao máximo a especialização, bem como a dependência de profissionais dentro do sistema criminal. A ideia de justiça local apresenta-se como um tribunal de iguais representações dos indivíduos de si mesmos, numa busca de solução entre equivalentes, sem a necessidade de um juiz. Nesse sentido, sobre a possibilidade de atuação de advogados e outros especialistas na gestão local do conflito, o autor propugna (CHRISTIE, 1977, p. 178) que eles não devem ocupar o papel principal e, se no caso concreto for inevitável a atuação desses expertos, devem ser vistos como auxiliares, não como dominantes no centro do conflito social.

Ainda que haja uma tendência à profissionalização da justiça restaurativa, decorrente de sua institucionalização, esses profissionais (mediadores, conciliadores, facilitadores), devem assumir um papel de orientação, cabendo aos envolvidos - ofensor e vítima - a condução dos processos de restauração para que não haja usurpação do lugar de fala dos afetados pelo conflito. Isto é, cabe à vítima e ao ofensor a condução da narrativa sobre o ato delitivo e a escolha das opções de como remediá-lo, de forma dialogada e horizontal. Ademais, conquanto seja necessário um arcabouço teórico para a aplicação das técnicas de justiça restaurativa, o ideal é que os membros da comunidade tornem-se os condutores dos processos restaurativos, o que afastaria os efeitos deletérios dessa tendência de profissionalização (SCHUCH, 2008, p. 505).

Uma das questões essenciais na devolução do conflito às vítimas, por meio de uma justiça que seja concebida horizontalmente, repousa na ideia de que os conflitos são positivos, como já mencionado, devendo ser valorizados, bem como não são de pertencimento do Estado, mas de cada parte envolvida - vítima e ofensor -, e de toda a comunidade. Isto é, do conflito pode haver resultados significativos para vítima, ofensor e comunidade (PALI, 2014, p. 34), o que não deve ser desprezado.

Em uma perspectiva profunda, também a prática restaurativa pode devolver à vítima, na visão do próprio agressor, a dignidade violada na prática do ato delitivo. Isso porque, no diálogo, também o autor do 
ato delitivo há de reconhecer a vítima como sujeito pleno em dignidade e não como objeto de sua ação (PEDRA, 2010, p. 94). Ainda, a Justiça Restaurativa pode evitar a vitimização secundária, na qual a vítima, desamparada, sofre novamente com o indevido funcionamento do sistema processual e com a irregular atuação da estrutura policial ou judiciária (FERNANDES, 1995, p. 38), sendo novamente vitimizada pela burocracia do modelo processual de justiça, que não a vislumbra na sua inteireza como sujeito do processo.

Desse arcabouço, a proposição da justiça horizontal contém os seguintes parâmetros (CRISTIE, 2011, p 118): a) as decisões possuem esteio local, porquanto o mesmo ato pode ser analisado de diferentes formas, de acordo com a comunidade que o analisa e, nesse sentido, cada comunidade pode estabelecer, de forma descentralizada, o que considera justo; b) as questões relevantes podem ser tratadas de maneira radicalmente diferente da forma que ocorre no sistema legal, pois não existem soluções pré-definidas, sendo relevante tudo aquilo que os participantes considerem como tal, de modo que cada caso concreto será administrado conforme a sua especificidade; c) a compensação é mais importante que a retribuição, visto que as "punições são particularmente disfuncionais em sistemas como esses (....) inflição consciente de dor - significa gerar uma guerra civil em sistemas frágeis.” (CHRISTIE, 2011, p. 118).

A ideia de justiça horizontalizada em que a reparação é mais importante que a retribuição - a utilização da pena como mal em resposta a outro mal anteriormente ocasionado (CHRISTIE, 2011) - é fundamental para o entendimento do que almeja a Justiça Restaurativa, em que são levadas a sério as especificidades de cada conflito penal, sem soluções pré-definidas e impostas verticalmente por uma autoridade central.

A Justiça Restaurativa, que tem como diretriz a noção de justiça horizontal, comunitária, ou local, de Nils Christie, baseia-se, como visto, no diálogo entre ofensor e vítima. Ou seja, ao invés do uso monopolizado da violência pelo Estado, seria oportunizado às partes encontrarem-se, quantas vezes fossem necessárias, para se chegar a uma solução consensual em relação ao dano causado, com a compreensão de se reduzir o sofrimento e aumentar as respostas positivas.

Como marco da Justiça Restaurativa, Howard Zehr explica que: 
O primeiro passo na justiça restaurativa é atender às necessidades imediatas, especialmente as da vítima. Depois disso, a justiça restaurativa deveria buscar identificar necessidades e obrigações mais amplas. Para tanto, o processo deverá, na medida do possível, colocar o poder e responsabilidade as mão diretamente dos envolvidos: a vítima e o ofensor. (ZEHR, 2008, p. 192)

O conceito de Justiça Restaurativa é amplo, aberto e fluido, como aponta Daniel Achutti:

E essa construção ainda em aberto e em constante movimento é, paradoxalmente, um importante ponto positivo da justiça restaurativa, pois não há um engessamento de sua forma de aplicação, e portanto, os casos-padrão e as respostas-receituário permanecerão indeterminados, na busca de adaptação a cada caso e aos seus conceitos culturas. (ACHUTTI, 2016, p. 66)

Pelo exposto, a partir do encontro da vítima e do ofensor, pode-se criar uma justiça de viés horizontalizado, que considere efetivamente a singularidade dos envolvidos no conflito, numa construção coletiva e participada da decisão, em virtude da fala e escuta respeitosa dos envolvidos, buscando-se a melhor maneira de lidar com o dano resultante do conflito, a fim de que se chegue a um ideal de justiça para aquele caso específico.

As características centrais da justiça restaurativa envolvem os seguintes aspectos: (a) participação da vítima nos debates sobre o caso, incluindo a deliberação sobre a maneira como os danos oriundos do conflito serão reparado; (b) o procedimento poderá não resultar em prisão para o ofensor, mesmo que venha a admitir que praticou o delito e eventuais provas corroborem a sua confissão; (c) é possível (e desejável) que as partes cheguem a um acordo sobre como lidar com a situação; e (d) os operadores jurídicos deixarão de ser os protagonistas do processo, abrindo espaço para uma abordagem mais ampla do conflito. (ACHUTTI, 2016, p. 85)

Nesse sentido, pelas críticas tecidas por Nils Christie ao sistema penal e pela construção do autor sobre a justiça comunitária e horizontalizada, pode-se dizer que a Justiça Restaurativa: a) não deve se apoiar em nenhum estereótipo das partes, nem da vítima - com a possibilidade 
de sobrevitimizá-la -, nem do ofensor - evitando sua estigmatização; b) permite com que os envolvidos no conflito sejam responsáveis pela administração e construção de uma solução adequada à violação penal, estimulando a participação ativa das partes na construção da decisão; c) deve distanciar-se da lógica burocrática, com a especialização e profissionalização dos envolvidos; d) deve ser acessível às partes, tanto pelo espaço destinado aos encontros quanto pela linguagem adequada e inteligível às partes; e) necessita ter seu foco na satisfação nas necessidades da vítima, do ofensor e da comunidade a partir do envolvimento e responsabilização de todos.

\section{A Justiça RESTAURATIVA E O PROTAGONISMO DA VÍTIMA COMO SUJEITO DE DIREITOS}

Para que a vítima possa ser compreendida como sujeito de direitos, primordialmente, é preciso superar o modelo jurisdicional tradicional de confiscação do conflito pelo Estado, com sua consequente neutralização, como desenvolvido até o momento no presente estudo. A crítica ao sistema jurisdicional tradicional repousa na ideia de que o tratamento dado à vítima não é adequado para que as suas necessidades sejam atendidas, não se escuta o seu sofrimento, ou suas mais diversas expectativas. Não há um esforço para restituir à vítima aquilo que ela perdeu, muito além dos bens materiais. Não se permite que a vítima auxilie de modo concreto como a sua própria situação conflituosa será resolvida.

Conforme exposto nos tópicos anteriores, decorre das imanações do próprio Estado Democrático de Direito que a vítima participe plenamente da construção da decisão em resposta ao dano que sofreu, numa mudança de paradigma do modelo tradicional para a construção de um modelo que se adéque às suas necessidades, reconhecendo-a como primordial interessada na reparação das consequências do delito. Aliás, não se trata, conforme insistentemente repetido, de reparação apenas financeira, mas emocional e até mesmo cognitiva.

Nessa linha, aposta-se na Justiça Restaurativa, como um mecanismo de consenso, uma plataforma de reparação nas mais diversas esferas, de acordo com as necessidades das vítimas. 
O que é preciso para que a vítima se recupere do dano que sofreu? Uma única resposta não existe. Esse ponto é crucial, pois explica o motivo de a pena como sanção, solução unívoca estatal, não ser a resposta mais adequada a todos os conflitos penais. Cada vítima possui uma expectativa própria, sentimentos próprios e específicos. Somente ela, em cada caso concreto, poderia responder com autenticidade o que poderia se feito para recomposição do dano sofrido.

Além da indenização por perdas materiais, as vítimas muitas vezes precisam que lhes sejam oportunizados momentos de fala para expressar as suas mais diversas emoções. As vítimas, se desejarem, devem poder expressar seus sentimentos de mágoa, raiva, medo, dor, como uma reação humana natural ao dano causado pelo delito. Elas precisam encontrar espaços para exteriorizar seus sentimentos e sofrimentos, para que falem e sejam ouvidas, respeitadas suas autonomias. Nesse sentido, a Justiça Restaurativa deve ser concebida de forma com que as vítimas possam realizar uma experiência de justiça, ter a concepção de uma vivência de algo real, o reconhecimento de houve um ato que lhe causou um dano e quais medidas podem ser tentadas a fim de corrigi-lo ou amenizá-lo. Não bastam as informações de que "medidas oficiais serão tomadas", porquanto as vítimas precisam ser informadas do que de fato ocorrerá e como elas podem contribuir para a solução do conflito. Isso é atuação participada, própria da noção de Estado Democrático de Direito. As informações precisam estar disponíveis para que a solução seja construída ouvindo-se os interessados, autores e destinatários das formas de justiça.

A Justiça Restaurativa deve levar a vítima a ser aparelhada quanto à melhor forma de solucionar o conflito penal, na medida em que a restituição - com o reconhecimento do erro e responsabilização dos envolvidos - torna-se mais eficaz que a retribuição com a pena. Ou seja, a restauração visa a correção do mal, sem a geração de mais violência, reconhecendo o valor ético da vítima.

(...) as vítimas precisam ser empoderadas. A justiça não pode simplesmente ser feita para e por elas. As vítimas precisam se sentir necessárias e ouvidas ao longo do processo. Uma das dimensões do mal é que elas foram despidas de poder, portanto, uma das dimensões de justiça deve ser a restituição desse poder. No mínimo, isso significa que elas devem ser a peça principal na 
determinação de quais são suas necessidades, e como e quando devem ser atendidas. Mas as vítimas deveriam participar de alguma forma do processo como um todo. (ZEHR, 2014, p.183)

A Justiça deve ser vivida, experienciada pelas vítimas, que não devem ser simplesmente informadas do processo, mas precisam passar pela experimentação da resolução do conflito. Por isso impõe-se seja permitido às vítimas usarem suas autonomias e as próprias liberdades para decidirem se querem tomar parte da construção da solução, mesmo que haja ainda mais sofrimento, porque é importante que seja apresenta as vítimas a possibilidade de vivenciar a justiça.

Conforme Zehr explica, uma das formas de empoderamento das vítimas para que suas necessidades sejam atendidas consiste na mediação vítima-ofensor (ZEHR, 2008, p. 192-193). Durante o processo de restauração, deve-se propiciar uma abordagem que atenda principalmente às trocas de informações entre a vítima, o ofensor e a comunidade, numa interação em que sejam afastados os estereótipos e atente-se à realidade dos envolvidos, com o propósito de solucionar a situação conflituosa. O autor explica que a mediação ente vítima e ofensor deve atender alguns pré-requisitos, tais como: que os participantes recebam apoio emocional necessário; que estejam dispostos a participar; que os mediadores sejam treinados; e que tudo aconteça no momento certo (ZEHR, 2008, p. 163). É preciso desmitificar a ideia de que a mediação se dê instantaneamente, ou em pouco tempo. Cada caso específico, de acordo com as necessidades da vítima e do ofensor, tomará o tempo que for necessário.

A mediação vítima-ofensor é uma estratégia, dentre outras, que permite a gestão local do conflito, que pode variar de caso a caso. De certo nem todas as situações de conflito penal permitirão a aplicação das técnicas de Justiça Restaurativas, de modo que os limites para a utilização das técnicas restaurativas deverão ser encontrados nas especificidades de cada conflito, sendo inviável, pelo que propõe esse novo modelo de justiça, o estabelecimento prévio de condicionantes, que funcionariam como amarras burocráticas aos afetos pelo conflito penal.

O Projeto de Lei $n^{0}$ 7006/2006 propõe alterações na legislação vigente para facultar o uso de práticas restaurativas no sistema de justiça criminal. Em seu artigo $8^{\circ}$ estabelece que "o procedimento restaurativo 
abrange técnicas de mediação pautadas nos princípios restaurativos”, realizados por "núcleos de prática restaurativa", compostos por profissionais da área da psicologia e serviço social, especialmente capacitados para essa função. O mesmo Projeto de Lei pretende alterar, ainda, o Código de Processo Penal para consignar que "os núcleos de justiça restaurativa serão integrados por facilitadores, incumbindo-lhes (...) utilizar as técnicas de mediação que forem necessárias para a resolução do conflito". O Projeto de Lei propõe o "uso facultativo e complementar" de procedimentos restaurativos "em casos de crimes e contravenções penais", a partir de alterações do Código Penal, do Código de Processo Penal e da Lei 9009/95. Ele não determina a quais crimes e contravenções se aplicará a Justiça Restaurativa, o que pode ser positivo, visto poder se abranger os mais diversos tipos penais, ou negativo, por existir a possibilidade de, na prática, só se encaminharem às praticas restaurativas os crimes de menor importância. Tudo dependerá dos esforços dos intérpretes na aplicação da norma.

A alteração no Código Penal se dá no sentido de que o Projeto de Lei 7006/2006 prevê a adição de dois dispositivos. Um seria responsável por estabelecer o cumprimento do acordo restaurativo como nova causa de extinção de punibilidade, com a inserção do inciso $\mathrm{X}$ ao artigo 107 do Código Penal. E outro, que acrescentaria às causas interruptivas de prescrição a homologação do acordo restaurativo, com a inserção do inciso VII ao artigo 117 do Código Penal.

Já o Código de Processo Penal sofreria alterações prevendo determinadas possibilidades: (a) a proposição de ação penal pelo Ministério Público seria facultativa enquanto estivesse em curso o procedimento restaurativo, com a inserção do $\S 4^{\circ}$ no artigo 24 do Código de Processo Penal - aqui se faz uma crítica, pois a melhor redação deveria ser aquela que não possibilita a proposição da ação penal, proibindo que corra em paralelo o processo tradicional e restaurativo; (b) a suspensão da ação penal quando recomendável o uso de práticas restaurativas, com a criação do artigo 93-A; e, c) a sugestão, pela autoridade policial, no relatório do inquérito, de encaminhamento das partes à restauração, com a inserção do $\S 4^{\circ}$ no artigo 10 .

O projeto de Lei 7006/2006 apresenta extensas possibilidades de encaminhamento de casos ao procedimento restaurativo, pela 
polícia, pelo magistrado, pelo Ministério Público, mas é omisso quanto à possibilidade de solicitação de encaminhamento pelas próprias partes, o que é paradoxal, no sentido de tudo o que foi discutido nesse texto. Partindo-se da ideia de que a Justiça Restaurativa, empodera as partes, especialmente a vítima, dando-lhe voz e espaço de escuta, é incompatível a obrigatoriedade de intervenção de uma autoridade para que o conflito seja gerido pelo viés da restauração.

Já a resolução da ONU 2002/2012, que trata sobre os princípios básicos para a utilização de programas de justiça restaurativa em matéria criminal, em seu preâmbulo, enfatiza que "a justiça restaurativa evolui como uma resposta ao crime que respeita a dignidade e a igualdade das pessoas, constrói o entendimento e promove harmonia social mediante a restauração das vítimas, ofensores e comunidades, além de propiciar às vítimas obterem reparação, se sentirem mais seguras e poderem superar o problema". Ainda declara em seu artigo $13^{\circ}$ que "as garantias processuais fundamentais que assegurem tratamento justo ao ofensor e à vítima devem ser aplicadas aos programas de justiça restaurativa e particularmente aos processos restaurativos".

Em maio de 2016, o Conselho Nacional de Justiça aprovou a Resolução 225/2016 que dispõe "sobre a Política Nacional de Justiça Restaurativa no âmbito do poder Judiciário”, destacando-se, em seu artigo $1^{\circ}$, a necessidade de prévio consentimento, livre e espontâneo dos participantes da Justiça Restaurativa, bem como o dever de serem informados de todos os procedimentos. $\mathrm{O}$ artigo $1^{\circ}$ da Resolução ainda assegura o direito de vítima e ofensor serem tratados de forma justa e digna, com mútuo respeito, bem como a garantia de que vítima e ofensor serão auxiliados a construir, a partir da reflexão e assunção de suas responsabilidades, "uma solução cabível e eficaz visando sempre o futuro".

No paradigma restaurativo, o crime não é concebido, portanto, como uma ação que viola o Estado ou a ordem jurídica, mas como lesão às pessoas e às suas relações intersubjetivas. O delito é, dessa forma, analisado por um viés fenomenológico, considerando como a manifestação de um conflito entre as partes, num contexto amplo e complexo. Existe a necessidade de diálogo entre o ofensor e a vítima, como maneira de se reequilibrar e, se possível, restaurar as mazelas sofridas pela vítima. Nesse sentido, a solução do conflito não é encontrada na lei, na jurisprudência ou em casos 
análogos, mas na própria relação mediada entre as partes, voltando-se para o futuro - o passado é a plataforma para uma solução prospectiva.

Sobre a Justiça Restaurativa e as críticas a ela apontadas, as mais recorrentes referem-se à necessidade de valoração de princípios jurídicos a ser observada no processo restaurativo e quanto à participação da vítima na decisão da "pena" que será aplicada ao ofensor (LARRAURI, 2004, p.87).

No que se refere às garantias jurídicas, as críticas à implementação da Justiça Restaurativa no Brasil apontam para uma eventual inobservância de princípios que orientam a prática criminal, como a legitimidade, obrigatoriedade e indisponibilidade da ação penal pública. Tais argumentos, ainda que marcados por uma concepção garantista do direito penal, revelam-se conservadores e ultrapassados, por justamente assegurarem a manutenção da intervenção penal muito além da mínima, fechando-se "as portas do direito penal a alternativas de não-punição, despenalização, reparação, perdão, aplicação de sanção não aflitivas” (SICA, 2007, p. 122).

Quanto à indisponibilidade da ação penal, essa premissa é própria da visão neutralizada da vítima no processo criminal e, como visto, resta superada, pois é possível não haver necessidade de persecução criminal devido ao ressarcimento do dano, reconciliação ou atuação de outras esferas de controle social que não por via do Direito Penal e Processual Penal. Em verdade, o fortalecimento do papel da vítima no processo está diretamente relacionado a supressão de uma cultura inquisitória, em que a resposta estatal é dada pelo juiz inquisidor e super parte, pela adoção de forma enfática e verdadeira de uma concepção acusatória para o processo penal. Apenas com a adoção definitiva do princípio dispositivo se permitirá que o propósito de visibilidade e empoderamento da vítima, como o seu reconhecimento como sujeito de direitos no processo penal (BARROS, 2008), seja alcançado.

Ainda sobre as garantias do contraditório e da ampla defesa, que as formas restaurativas não respeitariam, não restam vulneradas, porque o modelo consensual prevê a voluntariedade das partes, como pressuposto básico. Tal crítica somente tem amparo em uma perspectiva de contraditório como ação e reação. Na proposição de um contraditório dinâmico (BARROS, MARQUES, 2017, p. 348), que permite às partes atuarem no processo penal para construir a decisão permite a opção por 
uma proposição alternativa de solução do conflito. O direito à ampla defesa como ampla argumentação garante a atuação de todas as partes, inclusive acusado e vítima nas escolhas autônomas, estratégicas e informadas de possibilidades alternativas ao processo penal que discutirá e reconstruirá o caso penal (BARROS, 2009). Assim, sempre que considerarem devido, a vítima ou ofensor podem recusar o envio do caso ao procedimento restaurativo, permanecendo no modelo tradicional retributivo.

De toda forma, é certo que a Justiça Restaurativa não pode contrariar os princípios e regras constitucionais, violando o princípio da própria legalidade em sentido amplo. A aplicação do procedimento restaurativo deve respeitar as leis e tratados, conforme resolução da ONU 2002/2012: "nada que conste desses princípios básicos deverá afetar quaisquer direitos de um ofensor ou uma vítima que tenham sido estabelecidos no Direito Nacional e Internacional".

A utilização da Justiça Restaurativa deve ser vista como ampliação da proteção constitucional atribuída à vítima e ofensor, decorrentes do princípio da garantia da pessoa humana, porquanto considerados como sujeitos de direitos, autores e destinatários das formas de justiça a que se submeterão e atuarão de forma protagonizada.

\section{Considerações finais}

A compreensão atual, de um tratamento constitucional adequado à vítima, impõe uma diretiva vinculante: o seu reconhecimento como sujeito de direitos. A partir dessa perspectiva, na revisitação das concepções teóricas sobre a participação da vítima no processo penal, compreende-se que a expropriação do conflito pelo Estado e a consequente neutralização da vítima não se compatibilizam com a premissa de que, ao se reconhecer a vítima como sujeito de direitos, deve-se possibilitar a sua participação no processo penal, por meio de novos mecanismos ou estratégias de solução do conflito.

Nessa linha, o modelo consensual de solução de conflitos da Justiça Restaurativa apresenta-se como uma das possibilidades para a realização da justiça penal sem a deletéria marginalização ou ocultamento das vítimas de delitos, especialmente porque demarcado em planos de 
horizontalidade e diálogo, características capazes de atribuir aos sujeitos interessados a emancipação que requer o reconhecimento da vítima como sujeito de direitos. Confere-se à vítima a possibilidade de efetiva participação na resolução do conflito, permitindo-se que a solução possa ser conjugada no viés de uma reparação ampla, para além da exclusiva punição do ofensor ou recomposição do prejuízo moral, uma vez que a ofensa pode ter produzido efeitos emocionais e psicológicos profundos, o que o processo tradicional não é capaz de contemplar.

A jurisdição penal brasileira precisa reconhecer que a apreensão monocular dos conflitos penais - procedimentos unidirecionais e sanção padrão - representa opção teórica por um modelo de realização de justiça criminal que não mais se adéqua integralmente às novas visões constitucionais sobre os sujeitos processuais. É nesse espaço - em que o modelo vigente se excede ou se omite - que precisam ser experimentadas estratégias alternatiwvas, destacando-se, como potencialidade, a utilização da Justiça Restaurativa como mecanismo de horizontalização de conflitos penais e de reconhecimento das vítimas como sujeitos de direitos.

Não se quer, no entanto, que a utilização de técnicas restaurativas represente uma nova cooptação dos interessados no conflito penal por meio de técnicas de aliviamento das cargas do sistema processual penal tradicional. Há de ser aplicada a justiça horizontalizada, como proposta por Nils Christie, em sua melhor leitura, mantendo-se a integridade dos princípios irradiantes dessa ideia para que se mostre efetiva a tutela dos interesses da vítima.

De outro lado, a releitura constitucionalmente adequada da vítima como sujeito de direitos não pode conduzir em direção oposta, por meio de atribuição unilateral de podres, devendo-se cuidar para que a ampliação das faculdades das vítimas não sacrifique direitos e garantias processuais do autor do delito.

Pelo viés da Justiça Restaurativa, verifica-se a possibilidade de uma efetiva democratização quanto ao meio de solução de conflitos, afastando-se a resposta verticalizada do sistema penal para todos os casos, a partir da construção, em determinadas situações, de uma solução adequada pela vítima, comunidade e ofensor.

Nesse sentido, a Justiça Restaurativa, fundamentada na promoção da participação ativa das partes, com a interferência direta delas na 
formulação da decisão, alcança uma adequada construção intersubjetiva de justiça. Esse modelo almeja uma resposta mais humana, em que o processo penal não esteja voltado para a retribuição, mas para uma resposta dialogicamente construída entre vítima, ofensor e comunidade.

É no diálogo, de partes que se compreendem como iguais, em posição horizontal de interação, que se podem construir soluções que, em todo o processo, desde o cometimento do delito até a respectiva solução, se reconheçam os envolvidos como sujeitos de direitos, capazes de definir, em tecitura intersubjetiva, os rumos de suas existências.

\section{REFERÊNCIAS}

ACHUTTI, Daniel. Justiça Restaurativa e abolicionismo penal. São Paulo: Saraiva, 2018.

ACHUTTI, Daniel; PALLAMOLLA, Raffaella. Levando a justiça restaurativa à sério: análise crítica de julgados do Tribunal de Justiça do Rio Grande do Sul. Redes: Revista Eletrônica Direito e Sociedade, Canoas, v.5, n. 2, p. 279-289, nov. 2017. http://dx.doi.org/10.18316/redes.v5i2.4258.

ACHUTTI, Daniel; PALLAMOLLA, Raffaella. Justiça Criminal e Justiça Restaurativa: possibilidades de ruptura com a lógica burocrática-retribucionista. Revista Sistema Penal e Violência, Porto Alegre, v. 6, n. 1, p. 75-87, janeiro-junho 2014. http://dx.doi.org/10.15448/2177-6784.2014.1.16958

AMODIO, Ennio. Estetica della giustizia penale:prassi, media, fiction. Milano: Giuffrè, 2016.

ANITUA, Gabriel Ignácio. Histórias dos pensamentos criminológicos. Rio de Janeiro: Revan, 2008.

BARROS, Flaviane de Magalhães. A vítima de crimes e seus direitos fundamentais: seu reconhecimento como sujeito de direito e sujeito do processo. Revista de Direitos e Garantias Fundamentais, Vitória, n. 13, p. 309-334, jan./jun. 2013. http://dx.doi.org/10.18759/rdgf.v0i13.407

BARROS, Flaviane de Magalhães. A participação da vítima no processo penal. Rio de Janeiro: Lumen Juris, 2008.

BARROS, Flaviane de Magalhães. (Re)forma do processo penal. 2ed. Belo Horizonte: Del Rey, 2009. 
BARROS, Flaviane de Magalhães; MARQUES, Leonardo A. M. A atuação do juiz no contraditório dinâmico: uma análise comparativa entre o sistema processual penal adversarial chileno e o modelo constitucional de processo brasileiro. In: Leonel González. (Org.). Desafiando a Inquisição: ideias e propostas para a Reforma Processual Penal no Brasil. 1ed. Santiago Chile: Centro de Estudios de Justicia de las Américas, 2017, v. 1, p. 347-360.

BERISTAIN, Antonio. Nova criminologia à luz do direito penal e da vitimologia. Tradução de Cândido Furtado M aia Neto. Brasília: Editora Universidade de Brasília, 2000.

CAMPANÁRIO, Micaela Susana Nóbrega de Abreu. Mediação penal Inserção de meios alternativos de resolução de conflito Penal. Revista Civitas, Porto Alegre, v. 12, n. 1, p. 118-135 jan.-abr. 2013. http://dx.doi. org/10.15448/1984-7289.2013.1.12593

CHRISTIE, Nils. Conflicts as propety. The British Journal of Criminology, v.17. $\mathrm{n}^{\circ} 1.1977$.

CHRISTIE, Nils. Uma razoável quantidade de crime. Tradução de André Nascimento. Rio de Janeiro: Revan, 2011.

FERNANDES, Antônio Scarance. O papel da vítima no processo criminal. São Paulo: Malheiros, 1995.

FERNANDEZ, Daniela Bolivar. La mediación víctima-ofensor como alternativa al sistema penal: la perspectiva de las víctimas. Revista Sistema Penal e Violência, Porto Alegre, v. 6, n. 1, p. 13-30, janeiro-junho 2014. http://dx.doi. org/10.15448/2177-6784.2014.1.17224.

GOMES, Luiz Flávio; MOLINA, Antônio García-Pablos de. Criminologia. $3^{\mathrm{a}}$ ed. São Paulo: Revista dos Tribunais, 2000.

HABERMAS, Jurgen. Direito e democracia: entre faticidade e validade. Rio de Janeiro: Tempo Brasileiro, 1997. v. I e II.

HARDT, Michael; NEGRI, Antonio. Declaração Isto não é um manifesto. São Paulo: N1 edições, 2014.

JUNIOR, Heitor Piedade. Vitimologia evolução no tempo e espaço. Rio de Janeiro: Frei Bastos, 1993.

LARRAURI, Elena. Tendencias actuales de la justicia restauradora. Revista Brasileira de Ciências Criminais, São Paulo,, vol. 51/2004, p. 67 - 104, nov - dez de 2004. 
PALI, Brunilda. Justiça Ativa: processos de justiça restaurativa como campo fértil para o exercício da cidadania. Revista Sistema Penal e Violência, Porto Alegre, v. 6, n. 1, p. 31-42, janeiro-junho 2014. http://dx.doi. org/10.15448/2177-6784.2014.1.16721.

PEDRA JORGE BIROL, Alline. Alline. Justiça criminal versus restaurativa: com a palavra a vítima. In Joel Corrêa de Lima \& Rubens R. R. Casara (Coords.) Temas para uma perspectiva crítica do direito: homenagem ao professor Geraldo Prado. Rio de Janeiro: Lumen Juris, 2010.

PELIZZOLI, Marcelo L. Da Sombra social às inteligências sistêmicas dos conflitos. In: Justiça Restaurativa: caminhos da pacificação social. Pelizzoli, M.L. (Org.). Caxias do Sul: Ed. da UCS / Recife: Ed. da UFPE, 2016.

PRANIS, Kay. Processos circulares. Trad. Tônia Van Acker. São Paulo: Palas Athena, 2010.

SALM, João; LEAL, Jackson da Silva. A Justiça Restaurativa: multidimensionalidade humana e seu convidado de honra. Revista Sequência, n. 64, p. 195-226, jul. 2012. https://doi.org/10.5007/2177-7055.2012v33n64p195

SANTANA, Selma Pereira de. A vitimodogmática: uma faceta da justiça restaurativa? Revista Ciências Penais, São Paulo, vol. 11/2009, p. 321 - 348, Jul - Dez/2009.

SCHUCH, Patrice. Direitos e Afetos: Análise Etnográfica da “Justiça Restaurativa” no Brasil. Revista Antropología Y Derecho, CEDzAD, v. 7, p. 10-18, 2009.

SCHUCH, Patrice. Tecnologias da não-violência e modernização da justiça no Brasil: o caso da justiça restaurativa. Revista Civitas, Porto Alegre, v. 8, n. 3, p. 498-520, set.-dez. 2008. http://dx.doi.org/10.15448/1984-7289.2008.3.4872

SOUZA, Bárbara Fachinelli Nishi. O uso da mediação nos delitos sexuais: o resgate da dignidade da vítima. Revista Brasileira de Ciências Criminais, São Paulo, vol. 125/2016, p. 15 - 55, novembro 2016.

ZEHR, Howard. Trocando as lentes: um novo foco sobre o crime e a justiça. São Paulo: Palas Athena, 2008.

ZEHR, Howard; TOEWS, Maneiras de conhecer para uma visão restaurativa de mundo. In: Novas direções na governança da justiça e da segurança. Brasília: Ministério da Justiça, 2006. 


\section{Informações adicionais e declarações dos autores (integridade científica)}

Declaração de conflito de interesses (conflict of interest declaration): os autores confirmam que não há conflitos de interesse na realização das pesquisas expostas e na redação deste artigo.

Declaração de autoria e especificação das contribuições (declaration of authorship): todas e somente as pessoas que atendem os requisitos de autoria deste artigo estão listadas como autores; todos os coautores se responsabilizam integralmente por este trabalho em sua totalidade.

- Flaviane de Magalhães Barros Bolzan de Morais: projeto e esboço inicial, coleta e análise de dados, levantamento bibliográfico, revisão bibliográfica, redação, revisão crítica com contribuições substanciais, aprovação da versão final.

- José Afonso Neto: projeto e esboço inicial, coleta e análise de dados, levantamento bibliográfico, revisão bibliográfica, redação, revisão crítica com contribuições substanciais, aprovação da versão final.

- Yollanda Farnezes Soares: projeto e esboço inicial, coleta e análise de dados, levantamento bibliográfico, revisão bibliográfica, redação, revisão crítica com contribuições substanciais, aprovação da versão final.

Declaração de ineditismo e originalidade (declaration of originality): os autores asseguram que o texto aqui publicado não foi divulgado anteriormente em outro meio e que futura republicação somente se realizará com a indicação expressa da referência desta publicação original; também atestam que não há plágio de terceiros ou autoplágio. 
Dados do processo editorial

(http://www.ibraspp.com.br/revista/index.php/RBDPP/about/editorialPolicies)

- Recebido em: $18 / 12 / 2018$

- Controle preliminar e verificação de plágio: 22/12/2018

- Avaliação 1: 23/12/2018

- Avaliação 2: 31/12/2018

- Avaliação 3: 31/12/2018

- Decisão editorial preliminar: 20/01/2019

- Retorno rodada de correções: 05/02/2019

- Decisão editorial final: 08/02/2019

\section{COMO CITAR ESTE ARTIGO:}

BARROS BOLZAN DE MORAIS, Flaviane M.; AFONSO NETO, José; SOARES, Yollanda F. A justiça restaurativa como mecanismo de horizontalização de conflitos penais e de reconhecimento das vítimas como sujeito de direitos. Revista Brasileira de Direito Processual Penal, Porto Alegre, vol. 5, n. 1, p. 191-218, jan./abr. 2019. https://doi.org/10.22197/rbdpp.v5i1.210

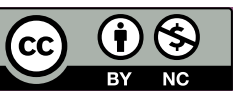

Esta obra está licenciada com uma Licença Creative Commons Atribuição-NãoComercial 4.0 Internacional. 